\title{
Successful treatment of early allograft dysfunction with cinacalcet in a patient with nephrocalcinosis caused by severe hyperparathyroidism: a case report
}

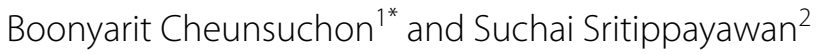

\begin{abstract}
Background: Hyperparathyroidism is common in patients undergoing kidney transplantation. Occasionally, this condition can cause early allograft dysfunction by inducing calcium phosphate deposition in the allograft, which results in nephrocalcinosis. Although nephrocalcinosis occurs occasionally in kidney allografts, it has only rarely been reported in the literature.

Case presentation: Here, we present the case of a 58-year-old Thai woman with severe hyperparathyroidism who received a living-related kidney transplant from her 35-year-old son. Our patient developed allograft dysfunction on day 2 post-transplantation despite good functioning graft on day 1 . Allograft biopsy showed extensive calcium phosphate deposition in distal tubules. She was treated with cinacalcet (a calcimimetic agent) and aluminum hydroxide. Allograft function was restored to normal within 1 week after transplantation with greatly reduced intact parathyroid hormone level.

Conclusion: Hyperparathyroidism in early functioning allograft causes elevated calcium and phosphate concentration in distal tubules resulting in nephrocalcinosis. The massive calcium phosphate precipitation obstructs tubular lumens, which leads to acute tubular dysfunction. Treatment of nephrocalcinosis with cinacalcet is safe and may improve this condition by increasing serum phosphate and reducing serum calcium and intact parathyroid hormone.
\end{abstract}

Keywords: Cinacalcet, Nephrocalcinosis, Early allograft dysfunction, Case report, Hyperparathyroidism

\section{Background}

Advances in tissue typing, crossmatching techniques, and immunosuppression have significantly reduced the risk of early renal allograft dysfunction due to immunological injury [1]. Although short-term graft survival is markedly improved, long-term graft outcome remains uncertain [1]. Recently, many studies have demonstrated the importance of nonimmunological processes (e.g., drug toxicity, infections, and recurrent/de novo glomerular diseases) that can cause allograft deterioration [2]. Nephrocalcinosis is a common finding in renal allografts,

\footnotetext{
*Correspondence: boonyarit.che@mahidol.ac.th

${ }^{1}$ Department of Pathology, Faculty of Medicine Siriraj Hospital, Mahidol University, 2 Prannok Road, Bangkok 10700, Thailand

Full list of author information is available at the end of the article
}

with an incidence of $80 \%$ at 10 years after transplantation [3]. However, nephrocalcinosis is rarely recognized as the cause of early allograft dysfunction [4]. Here, we present a histological finding of nephrocalcinosis in a renal allograft of a patient with early graft dysfunction. Clinical findings, possible etiologies, pathogenesis, and treatment are all briefly discussed.

\section{Case presentation}

A 58-year-old Thai woman developed end-stage renal disease from lupus nephritis and had been on hemodialysis for 2 years. She had markedly elevated serum intact parathyroid hormone (iPTH) of $113.8 \mathrm{pmol} / \mathrm{L}$ (1.6-6.9 pmol/L), increased serum calcium $(\mathrm{Ca})$ of $2.65 \mathrm{mmol} / \mathrm{L}(2.10-2.37 \mathrm{mmol} / \mathrm{L})$, and a phosphorus 
(P) level of $1.39 \mathrm{mmol} / \mathrm{L}(1.13-1.78 \mathrm{mmol} / \mathrm{L})$. She was on Lanthanum carbonate, later converted to aluminum hydroxide, but was not on 1 alpha cholecalciferol, vitamin D analogs or calcium supplements. Daily urine output was $130 \mathrm{~mL}$ and her urine $\mathrm{pH}$ was high at 7.5 without urinary tract infection or sodium bicarbonate use. On 26 March 2014, our patient received a renal transplant from her haplo-identical and compatible blood group 35-yearold son. The radionuclide renogram demonstrated normal function of both of the donor's kidneys. Pretransplant luminex crossmatch and panel reactive antibody tests were negative. Parathyroid sestamibi scan was not done because the doctor and patient did not want to do a parathyroidectomy. Cinacalcet (50 $\mathrm{mg}$, once a day), a calcimimetic agent, and aluminum hydroxide $\left(\mathrm{Al}(\mathrm{OH})_{3}\right)$ (1000 $\mathrm{mg}$, three times a day) were prescribed for 2 days prior to transplantation. Serum $\mathrm{Ca}, \mathrm{P}$, and $\mathrm{iPTH}$ were decreased to $2.20,1.74 \mathrm{mmol} / \mathrm{L}$, and $92 \mathrm{pmol} / \mathrm{L}$ at the time of transplantation, respectively (Fig. 1). Induction therapy consisted of tacrolimus, mycophenolate mofetil, and steroid without interleukin-2 receptor antagonists as indicated in institutional protocol.

The patient had immediate graft function with $3000 \mathrm{~mL}$ of urine during day 1 after transplantation. However, urine output decreased to $1150 \mathrm{~mL}$ on day 2, with serum $\mathrm{Ca}, \mathrm{P}$, and $\mathrm{iPTH}$ levels increased to $2.33 \mathrm{mmol} / \mathrm{L}, 1.65 \mathrm{mmol} / \mathrm{L}$, and $137.4 \mathrm{pmol} / \mathrm{L}$, respectively (Fig. 1). Serum creatinine (SCr) was significantly elevated to $280 \mu \mathrm{mol} / \mathrm{L}$ on day 4 . Doppler ultrasound of the transplanted kidney showed no hydronephrosis or vessel-related problems. Cinacalcet
(25 mg) and $\mathrm{Al}(\mathrm{OH})_{3}$ were restarted again on day 2 . Intravenous furosemide was also prescribed to enhance urine output. Tacrolimus level were $6.5-11.9 \mathrm{ng} / \mathrm{mL}$. Hemodialysis was started and allograft biopsy was performed on day 2 after transplantation. The graft biopsy contained 25 glomeruli with no presence of glomerulitis or fibrin thrombi. There were, however, more than 20 foci of intratubular basophilic crystals (Fig. 2a). The crystals were positive for von Kossa stain, indicating calcium phosphate precipitation (Fig. 2b). Under polarized light, crystals showed no birefringence that is characteristic of calcium oxalate. Interestingly, all of the crystals were located in the distal tubules. There was no evidence of tubular injury or rejection. Immunofluorescence studies for IgG, IgA, IgM, C3, C1q, kappa, lambda, fibrinogen, and C4d were all negative. The histopathological diagnosis was nephrocalcinosis caused by intratubular precipitation of calcium phosphate crystals, most likely due to severe hyperparathyroidism. Urine $\mathrm{pH}$ before and 1 day after transplantation was 7.5 and 6.0, respectively. Our patient did not use any phosphate-containing laxatives. We withheld the cinacalcet for $24 \mathrm{~h}$ due to a high urine calcium/creatinine $(\mathrm{Ca} / \mathrm{Cr})$ ratio $(0.57 \mathrm{mmol} / \mathrm{mmol})$, but restarted later after the ratio was decreased to 0.08 and continued for 1 week without any change in immunosuppressive agents. $\mathrm{SCr}$ and $\mathrm{iPTH}$ declined to less than $176.8 \mu \mathrm{mol} / \mathrm{L}$ and $21.2 \mathrm{pmol} / \mathrm{L}$, respectively, while serum $\mathrm{Ca}, \mathrm{P}$, and urine $\mathrm{pH}$ were maintained between $2.10-2.25 \mathrm{mg} / \mathrm{dL}, 0.87-1.32 \mathrm{mmol} / \mathrm{L}$, and 5.5-6.0, respectively. Only one hemodialysis treatment was required.

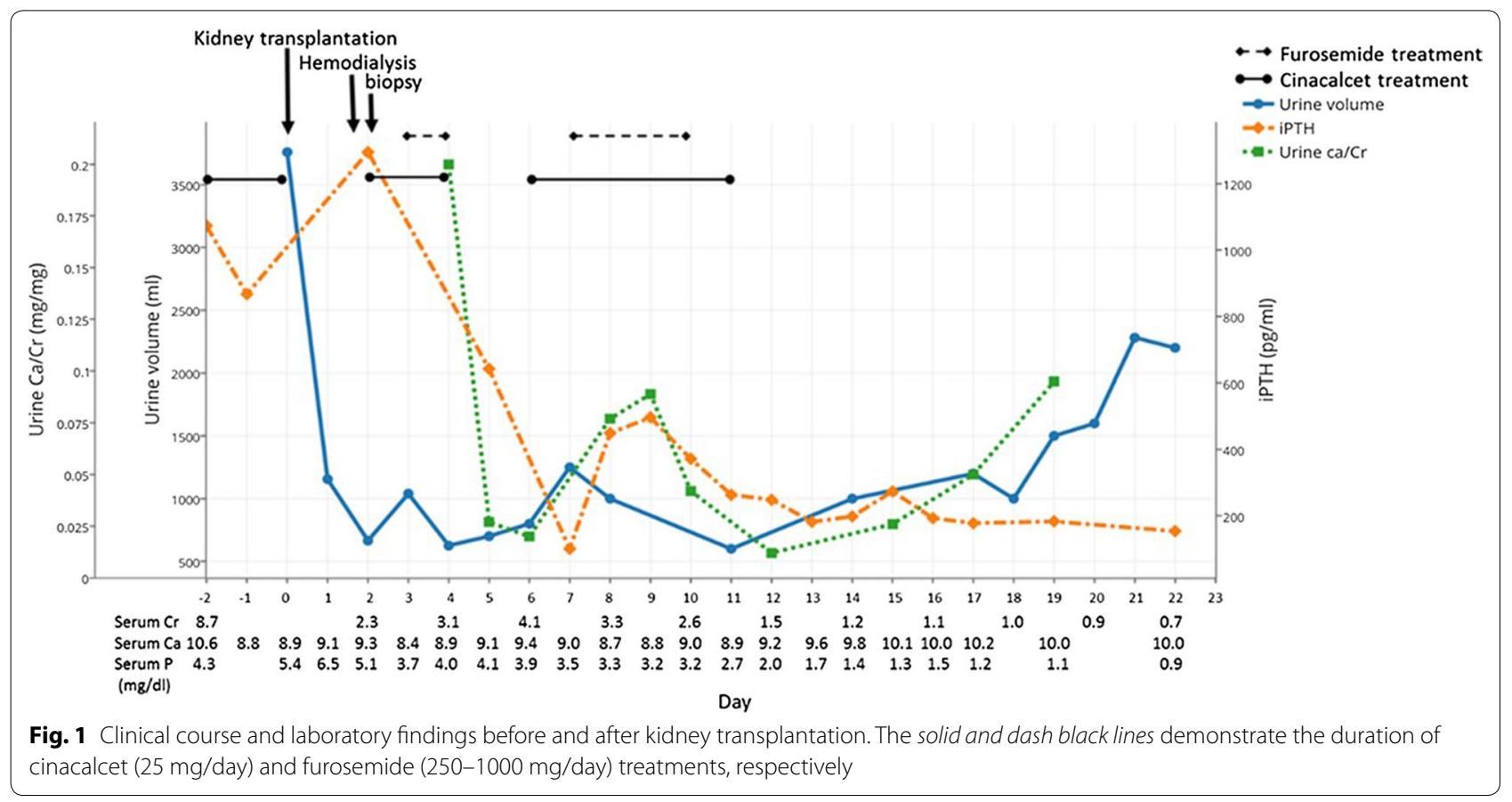



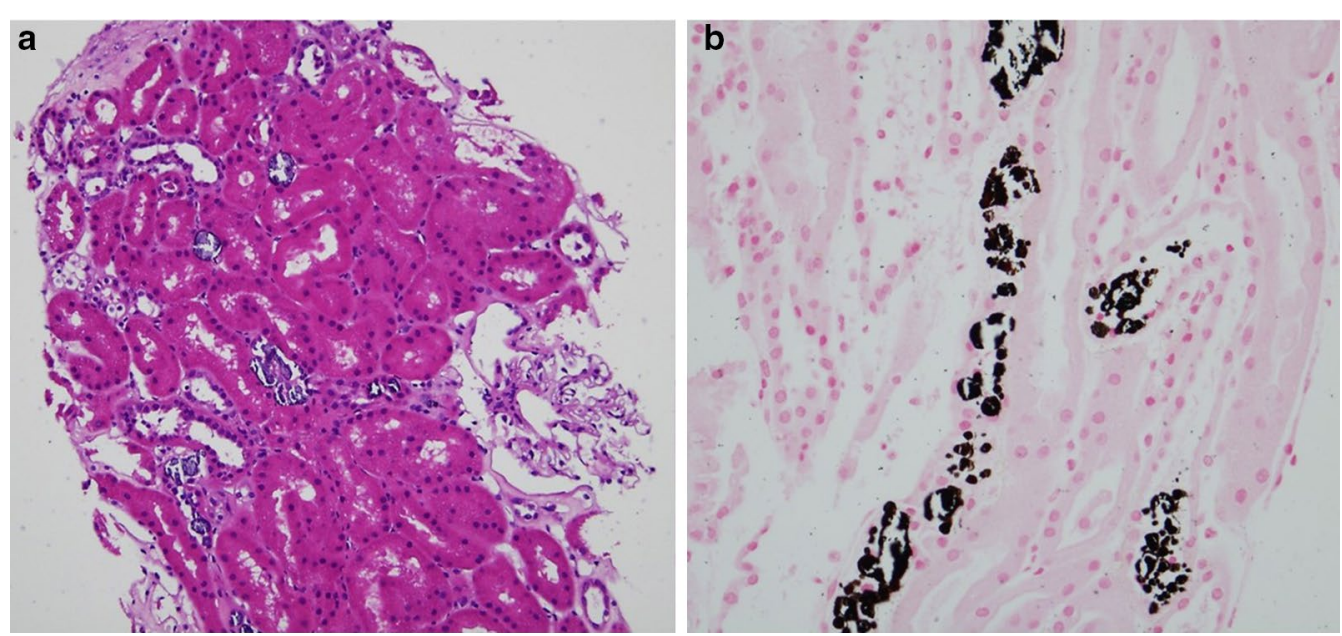

Fig. 2 a Numerous intratubular calcium crystals are noted in the tubular lumens. The absence of interstitial inflammatory cell infiltration rules out acute $T$ cell-mediated rejection ( $H \& E$ stain, original magnification $\times 200$ ). b Presence of calcium phosphate crystals proven by von Kossa staining (von Kossa stain $\times 400)$

At 2 years after transplantation, our patient has slightly high serum iPTH (13.8-21.2 pmol/L) and Ca $(2.65 \mathrm{mmol} / \mathrm{L})$ levels, with low level of serum $\mathrm{P}$ (0.84 $\mathrm{mmol} / \mathrm{L})$. Current immunosuppressive agents include tacrolimus, mycophenolate mofetil, and prednisolone.

\section{Discussion}

Nephrocalcinosis can be found as early as 6 weeks (6\% in protocol biopsies) after transplantation [5]. The incidence progressively increases to almost $80 \%$ by 10 years after transplantation [3]. The presence of nephrocalcinosis in renal allografts was found to be associated with chronic allograft nephropathy [5]. Although nephrocalcinosis effect was not significant in the short-term, the long-term consequences were unclear [6]. A possible etiology of nephrocalcinosis in this patient may have been metabolic derangement associated with severe hyperparathyroidism. Nephrocalcinosis was more frequently seen in allograft patients with hyperparathyroidism than in those without this condition $[5,6]$. Hyperparathyroidism increases the filtered load of calcium from high serum calcium level and decreases phosphate reabsorption in proximal tubules, both of which elevate calcium and phosphate concentrations in distal tubules. Our patient also had high urine $\mathrm{pH}$ (7.5) before transplantation, which enhanced calcium phosphate precipitation. Unfortunately, we have no data on urine citrate, ammonium, and sulfate levels, which might help to indicate the cause of the high urine $\mathrm{pH}$ in this patient. Calcium phosphate precipitation also causes tubular cell injury, which causes the distal tubules to express proteins, such as osteopontin and hyaluronan. These molecules promote calcium phosphate adhesion to the surface of tubular cells [7]. Massive calcium phosphate precipitation causes tubular obstruction, which leads to acute allograft dysfunction.

Calcineurin inhibitors were associated with nephrocalcinosis in renal allografts. However, the incidence was decreased in later study and found not to be different from calcification due to acute tubular necrosis [8]. This was probably the result of reduced dose of immunosuppressive agents used in current practice.

Hyperparathyroidism is common in patients undergoing renal transplantation. Association has been established between hyperparathyroidism and delayed graft function [9]. Although some reports appear in the literature [4, 10-13], all of the reports are single-patient case reports (none are large case series) of patients with early graft dysfunction and nephrocalcinosis (Table 1). Among those patients, nephrocalcinosis was detected as early as 5 days after transplantation. Four of 5 cases showed concurrent lesions (3 acute tubular necrosis, 1 borderline rejection). Serum calcium and phosphate levels varied from normal to markedly increased. Two patients had improved graft function after supportive treatment and two others required parathyroidectomy. Only one patient had graft failure, which was found to be caused by gradual increase in calcium crystal deposition in the follow-up biopsy.

Cinacalcet is a novel phenylalkylamine type II calcimimetic agent that allosterically modulates the calcium sensing receptor by increasing the sensitivity of the receptor to extracellular calcium, which leads to suppression of PTH transcription, secretion, and parathyroid gland hyperplasia. Activation of the calcium sensing 


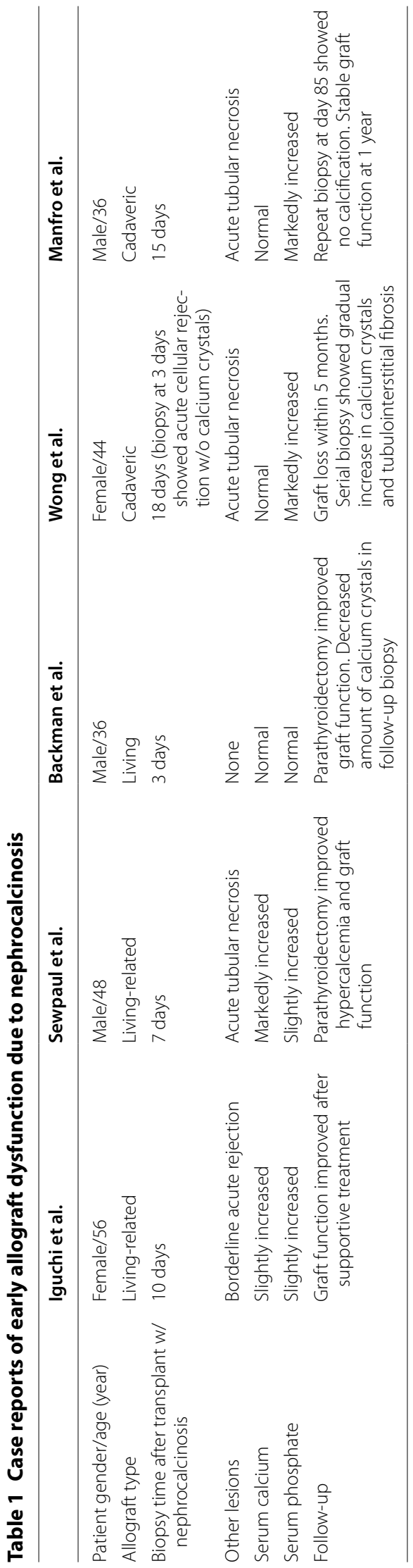


receptor inhibits phosphate reabsorption at the proximal tubule and sodium chloride reabsorption at the thick ascending limb of Henle loop, which promotes calciuria as a result of the reduction in passive paracellular calcium reabsorption. Cinacalcet was approved by the United States Food and Drug Administration for treatment of parathyroid cancer and hyperparathyroidism in endstage renal disease patients [14]. The benefit of a calcimimetic agent in post-renal transplant hyperparathyroidism was demonstrated in a randomized controlled trial [15]. In that study, cinacalcet demonstrated an ability to significantly increase serum phosphorus level and decrease serum calcium and iPTH over the study's 52-week duration. In contrast to results from other case reports and retrospective studies, three studies in nephrocalcinosis that developed in transplanted kidneys found that cinacalcet did not significantly decrease glomerular filtration rate or increase urinary calcium excretion [16-18]. To date, no strong evidence has been presented that suggests that cinacalcet worsens kidney graft function or that it is associated with other severe adverse effects after transplantation. Urgent parathyroidectomy was recommended by a previous case report to improve graft function in a poorly-controlled hyperparathyroidism patient who experienced graft dysfunction due to acute tubular necrosis associated with intratubular calcification [12]. The use of calcimimetic agent in this condition has not been previously reported. We demonstrated the efficacy of cinacalcet in decreasing serum intact PTH level and calcium level and improving graft function in a patient with poorly-controlled severe hyperparathyroidism who developed early graft dysfunction from intratubular calcium deposition immediately after transplantation. Immediate graft function in a setting of high urine $\mathrm{pH}$ and hyperparathyroidism-associated hypercalciuria and hyperphosphaturia may have caused calcium phosphate crystallization in this patient. During acute kidney injury, urine $\mathrm{Ca} / \mathrm{Cr}$ ratio was found to be associated with furosemide and cinacalcet therapy. Whether the increase in the urine $\mathrm{Ca} / \mathrm{Cr}$ ratio was due to high urine calcium or low urine creatinine has yet to be established. In any case, our patient's kidney function was improved within one week after starting cinacalcet treatment, with accompanying decreases in serum calcium and iPTH. At time of discharge, our patient had good kidney function $(\mathrm{SCr}$ $67.2 \mathrm{mg} / \mathrm{dL}$ ), but still had a slightly elevated iPTH that ranged from 15.9 to $21.2 \mathrm{ng} / \mathrm{L}$.

\section{Conclusion}

Severe hyperparathyroidism can cause early allograft dysfunction from intratubular calcium crystal obstruction after kidney transplantation. Perioperative treatment with cinacalcet was safe and effective in reversing the effects of nephrocalcinosis and improving kidney function in this patient.

\section{Abbreviations \\ $\mathrm{Al}(\mathrm{OH})_{3}$ : aluminum hydroxide; Ca: calcium; iPTH: intact parathyroid hormone; P: phosphorus; SCr: serum creatinine.}

\section{Authors' contributions}

BC interpreted and reported the kidney biopsy. SS managed the patient. Both authors wrote, read, and approved the final version of the manuscript.

\section{Author details \\ ${ }^{1}$ Department of Pathology, Faculty of Medicine Siriraj Hospital, Mahidol University, 2 Prannok Road, Bangkok 10700, Thailand. ${ }^{2}$ Division of Nephrol- ogy, Department of Medicine, Faculty of Medicine Siriraj Hospital, Mahidol University, Bangkok, Thailand.}

\section{Acknowledgements \\ None.}

\section{Competing interests}

The authors hereby declare no personal or professional conflicts of interest regarding any aspect of this study.

\section{Availability of data and materials}

Data will not be shared due to patient confidentiality.

\section{Consent to publish}

Written informed consent was obtained from the patient for publication of this Case Report and any accompanying images.

\section{Publisher's Note}

Springer Nature remains neutral with regard to jurisdictional claims in published maps and institutional affiliations.

Received: 22 August 2016 Accepted: 4 April 2017

Published online: 08 April 2017

References

1. Lamb KE, Lodhi S, Meier-Kriesche HU. Long-term renal allograft survival in the United States: a critical reappraisal. Am J Transpl. 2011;11:450-62.

2. Nankivell BJ, Kuypers DRJ. Diagnosis and prevention of chronic kidney allograft loss. Lancet. 2011;378:1428-37.

3. Nankivell BJ, Borrows RJ, Fung CL-S, O'Connell PJ, Allen RDM, Chapman $J R$. The natural history of chronic allograft nephropathy. New Engl J Med. 2003;349:2326-33.

4. Wong PN, Chan AN, Lo KY, Wong YY, Mak SK, Wong AK. Kidney allograft failure due to acute phosphate nephropathy associated with severe secondary hyperparathyroidism. Nephrol Dial Transpl Plus. 2011;4:324-6.

5. Schwarz A, Mengel M, Gwinner W, Radermacher J, Hiss M, Kreipe H, et al. Risk factors for chronic allograft nephropathy after renal transplantation: a protocol biopsy study. Kidney Int. 2005;67:341-8.

6. Gwinner W, Suppa S, Mengel M, Hoy L, Kreipe HH, Haller H, et al. Early calcification of renal allografts detected by protocol biopsies: causes and clinical implications. Am J Transpl. 2005;5:1934-41.

7. Vervaet BA, Verhulst A, D'Haese PC, De Broe ME. Nephrocalcinosis: new insights into mechanisms and consequences. Nephrol Dial Transpl. 2009;24:2030-5.

8. Solez K, Racusen LC, Marcussen N, Slatnik I, Keown P, Burdick JF, et al. Morphology of ischemic acute renal failure, normal function, and cyclosporine toxicity in cyclosporine-treated renal allograft recipients. Kidney Int. 1993:43:1058-67.

9. Torregrosa J, Campistol J, Fenollosa B, Montesinos M, Romar A, Martinez de Osaba M. Role of secondary hyperparathyroidism in the development of post-transplant acute tubular necrosis. Nephron. 1996;73:67-72. 
10. Backman U, Butler G, Fletchner P, McMullin J. A case study with delayed renal graft function as a consequence of severe secondary hyperparathyroidism. Artif Organs. 1995;19:72-5.

11. Iguchi S, Nishi S, Shinbo J, lino N, Kazama JJ, Shimada H, et al. Intratubular calcification in a post-renal transplanted patient with secondary hyperparathyroidism. Clin Transpl. 2001;15:51-4.

12. Sewpaul A, Sayer JA, Mohamed MA, Ahmed A, Shaw M, Prabhu VR, et al. Rapid onset intratubular calcification following renal transplantation requiring urgent parathyroidectomy. Clin Nephrol. 2007;68:47-51.

13. Manfro RC, Pedroso JA, Pegas KL, Gonçalves LFS. Acute phosphate nephropathy in a kidney transplant recipient with delayed graft function. Transplantation. 2009;87:618-9.

14. Brown EM. Clinical lessons from the calcium-sensing receptor. Nat Clin Pract Endoc. 2007;3:122-33.
15. Evenepoel P, Cooper K, Holdaas H, Messa P, Mourad G, Olgaard K, et al. A randomized study evaluating cinacalcet to treat hypercalcemia in renal transplant recipients with persistent hyperparathyroidism. Am J Transpl. 2014;14:2545-55

16. Peng LW, Logan $J$, James SH, Scott KM, Lien YH. Cinacalcet-associated graft dysfunction and nephrocalcinosis in a kidney transplant recipient. Am J Med. 2007;120(9):e7-9. doi:10.1016/j.amjmed.2005.09.041.

17. Courbebaisse M, Diet C, Timsit M-O, Mamzer M-F, Thervet E, Noel L-H, et al. Effects of cinacalcet in renal transplant patients with hyperparathyroidism. Am J Nephrol. 2012;354:341-8.

18. Esposito L, Rostaing L, Gennero I, Mehrenberger M, Durand D, Kamar N. Hypercalciuria induced by a high dose of cinacalcet in a renal-transplant recipient. Clin Nephrol. 2007;68:245-8.

\section{Submit your next manuscript to BioMed Central and we will help you at every step:}

- We accept pre-submission inquiries

- Our selector tool helps you to find the most relevant journal

- We provide round the clock customer support

- Convenient online submission

- Thorough peer review

- Inclusion in PubMed and all major indexing services

- Maximum visibility for your research

Submit your manuscript at www.biomedcentral com/submit 